Check for updates

Cite this: Metallomics, 2018, 10,73

Received 9th October 2017, Accepted 13th December 2017

DOI: $10.1039 / \mathrm{c} 7 \mathrm{mt} 00285 \mathrm{~h}$

rsc.li/metallomics

\section{Single-cell analysis by ICP-MS/MS as a fast tool for cellular bioavailability studies of arsenite $\dagger$}

\author{
S. Meyer, iD $\ddagger^{a b}$ A. López-Serrano, $\ddagger^{c}$ H. Mitze, ${ }^{a}$ N. Jakubowski iD ${ }^{c}$ and \\ T. Schwerdtle (iD *abd
}

\begin{abstract}
Single-cell inductively coupled plasma mass spectrometry (SC-ICP-MS) has become a powerful and fast tool to evaluate the elemental composition at a single-cell level. In this study, the cellular bioavailability of arsenite (incubation of 25 and $50 \mu \mathrm{M}$ for $0-48 \mathrm{~h}$ ) has been successfully assessed by SC-ICP-MS/MS for the first time directly after re-suspending the cells in water. This procedure avoids the normally arising cell membrane permeabilization caused by cell fixation methods (e.g. methanol fixation). The reliability and feasibility of this SC-ICP-MS/MS approach with a limit of detection of $0.35 \mathrm{fg}$ per cell was validated by conventional bulk ICP-MS/MS analysis after cell digestion and parallel measurement of sulfur and phosphorus.
\end{abstract}

In recent years, a growing interest in single-cell analysis could be recognized and numerous analytical methods have been developed or improved to allow the analysis of individual cells and their cellular compartments. ${ }^{1-3}$ Analysis of individual cells provides highly valuable information on cell to cell variance especially within an isogenic cell population. To date, the most traditional analytical methods to determine, for example, cellular bioavailability of metals involve the analysis of a large amount of cells after lysis, extraction or digestion. ${ }^{4,5}$ The results provide integrated information from thousands of cells and mask the stochastic diversity of the individual cellular response.

Inductively coupled plasma mass spectrometry (ICP-MS), nowadays the most advanced and sensitive tool for ultra-trace element analysis, has already been established for single-cell analysis (SC-ICP-MS). In SC-ICP-MS, cells are embedded in droplets generated by conventional nebulization and are directly introduced

\footnotetext{
${ }^{a}$ Institute of Nutritional Science, University of Potsdam, Arthur-Scheunert-Allee 114-116, 14558 Nuthetal, Germany.E-mail: tanja.schwerdtle@uni-potsdam.de

${ }^{b}$ NutriAct - Competence Cluster Nutrition Research Berlin-Potsdam, Germany

${ }^{c}$ Bundesanstalt für Materialforschung und - prüfung (BAM),

Richard-Willstätter-Str. 11, 12489 Berlin, Germany

${ }^{d}$ Interactions of Essential Trace Elements in Healthy and Diseased Elderly (TraceAge), DFG Research Unit, FOR 2558, Nuthetal, Germany

$\dagger$ Electronic supplementary information (ESI) available. See DOI: 10.1039/c7mt00285h

\$ Both authors contributed equally to this study.
}

into the plasma. After vaporization, each cell generates an ion cloud which is detected as an individual spike signal using short dwell times. Its intensity is proportional to the quantity of the analyte ions present in a single-cell, and the number of spike signals is proportional to the number of cells containing the analyte of interest. SC-ICP-MS has already been applied in single-cell analysis to determine minerals such as calcium and magnesium. ${ }^{6,7}$ Quantitative analysis was also successfully applied to assess the cellular uptake of $\mathrm{TiO}_{2}$ and $\mathrm{Ag} .{ }^{8}$

In this study, the main analytical characteristics of SC-ICP-MS were optimized and validated for the quantitative analysis of arsenic in human epithelial lung adenocarcinoma cells (A549, American Type Culture Collection, CL- $185^{\mathrm{TM}}$ ) after incubation with arsenite (iAs ${ }^{\mathrm{III}}$ ). The cells were cultivated in Dulbecco's modified Eagle's medium (DMEM, Sigma Aldrich) containing $10 \%$ fetal calf serum (PAA Laboratories) and penicillin (100 U)/ streptomycin $\left(100 \mu \mathrm{g} \mathrm{L} \mathrm{L}^{-1}\right)$ (both Sigma-Aldrich) at $37{ }^{\circ} \mathrm{C}$ in $5 \% \mathrm{CO}_{2}$ and $100 \%$ humidity as described elsewhere. ${ }^{9}$ After $24 \mathrm{~h}$ of logarithmical growing, the cells were incubated with iAs ${ }^{\text {III }}$ (Sodium arsenite, Sigma-Aldrich, purity $>99.99 \%$ ) for increasing exposure times $(0,2,6,16,24$ and $48 \mathrm{~h}$ ) to monitor uptake kinetics at the single-cell level. Stock solutions were freshly prepared for each experiment in sterile deionized water.

After incubation with iAs ${ }^{\mathrm{III}}$, the cells were detached from culture dishes by trypsinization, washed with ice-cold PBS buffer, counted (Casy TTC, OLS OMNI Life Science) and pelletized by centrifugation (for further details see ref. 9). Immediately after centrifugation the cell pellets were re-suspended in ice-cold deionized water to a final density of 250000 cells per $\mathrm{mL}$ and directly analyzed by SC-ICP-MS/MS (Agilent 8800 ICPQQQ, Agilent Technologies). The cell integrity was checked by microscopic evaluation (Fig. 1) indicating that the cells remained intact for the time of measurement.

In contrast to cell fixation procedures used in other studies, ${ }^{7,10}$ this unsophisticated procedure avoids cell membrane permeabilization, thereby minimizing the loss of cytosolic metal species. 


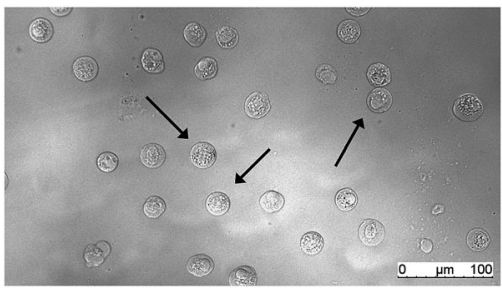

Fig. 1 Microscopy image of A549 cells re-suspended in deionized water for SC-ICP-MS/MS.

\section{Single-cell analysis optimization}

In SC-ICP-MS, short dwell times are needed to achieve a higher signal-to-noise ratio since shorter dwell times decrease the background signal, while the analyte intensity signal remains constant. In addition, a short dwell time ensures that the spike signals relate just to one cell which is a mandatory prerequisite for SC-ICP-MS.

In this study, dwell times of 3 and $10 \mathrm{~ms}$ were tested to assess arsenic (As) amounts at a single-cell level. The number of As spike cell events were counted by measuring the cells incubated with $50 \mu \mathrm{M}$ iAs ${ }^{\mathrm{III}}$ for $24 \mathrm{~h}$. To differentiate between noise and cell event signals only As spike signals higher than the 3-fold background level were counted.

A decrease in the dwell time from 10 to $3 \mathrm{~ms}$ resulted in a 2.5-fold increase in detected cell events (119 compared to 297 in the same period of time, respectively (ESI, $\dagger$ Fig. S1)). Because the lifetime of a single-cell ion cloud generated by the plasma is shorter than both tested dwell times, the lower dwell time of $3 \mathrm{~ms}$ reduces the risk to measure coexistences. Moreover, lower dwell times imply a greater number of As spike cell events. The resolution is higher and this positively affects the As mass calculations. Thus, a dwell time of $3 \mathrm{~ms}$ was chosen for all experiments carried out in this study.

\section{Transport efficiency}

Another important parameter to be determined in SC-ICP-MS is the transport efficiency. Transport efficiency is defined as the ratio of the amount of analyte entering the plasma and reaching the detector to the amount of aspirated analyte. ${ }^{11}$ First, the transport efficiency of standard solutions was indirectly estimated by comparing the sample uptake volume to the waste volume over a defined period of time. An average value of $7.5 \%$ was estimated for the transport efficiency of standard solutions.

For cells, the transport efficiency was determined using sulfur and phosphorus, especially since both elements occur in cellular macromolecules including DNA, proteins as well as the membrane building phospholipids. Unfortunately, these two elements are challenging in single quadrupole ICP-MS detection, but ICP-MS/MS offers the option to work with oxygen as a reaction gas so that both elements can be effectively separated from disturbing interferences (for further ICP-MS/MS parameters see Table S1, ESI $\dagger$ ). ${ }^{12}$ For both elements distinct
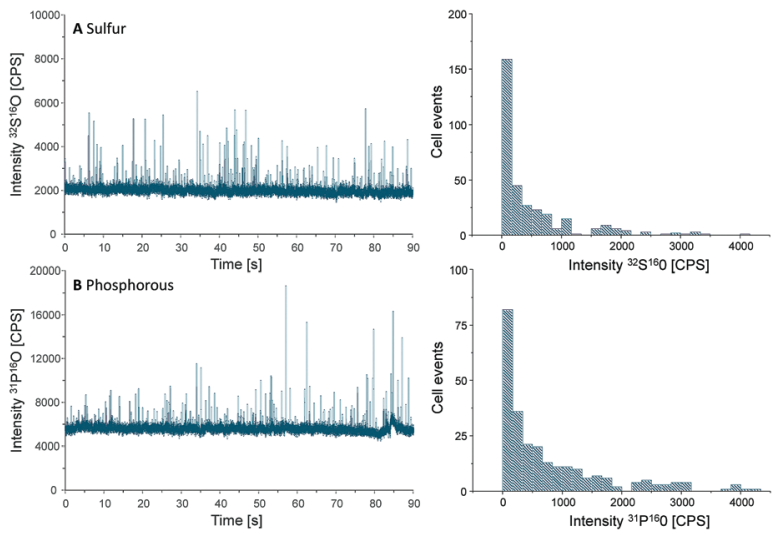

Fig. 2 Chromatograms and histograms of cells analyzed by SC-ICP-MS/MS using oxygen as reaction gas. The results obtained for sulfur $(A)$ and phosphorus (B) are displayed.

spike signals were observed and cell events were counted to calculate the transport efficiency (Fig. 2).

Because the cell density of the cell suspension was set to 250000 cells per $\mathrm{mL}$, a sample uptake $\left(0.167 \mathrm{~mL} \mathrm{~min}^{-1}\right)$ of $90 \mathrm{~s}$ results in 62000 cells sprayed in the nebulizer. In the case of sulfur, 330 cell events were detectable within this period of time, resulting in a transport efficiency of $0.53 \%$, compared to $0.42 \%$ for phosphorus where 260 events were recorded. This value agrees with the typical cell transport efficiency values reported for mammalian cells (diameter $10-20 \mu \mathrm{m}$ ). ${ }^{6}$ According to these results an average transport efficiency of $0.5 \%$ was applied for all calculations of this study. This low cell transport efficiency has to be improved in further studies e.g. by the use of more effective nebulizers or smaller spray chambers.

\section{Quantitative analysis of As at a single-cell level}

To calculate the As amount in A549 cells at a single-cell level, external calibration with As standard solutions $(0,25,50$ and $75 \mu \mathrm{g} \mathrm{L}^{-1}$ ) was used. A linear calibration curve of ICP-MS/MS intensities of $m / z^{75} \mathrm{As}^{16} \mathrm{O}$ was obtained $\left(R^{2}=0.9998\right)$ and the limit of detection (LOD) was calculated to be $0.35 \mathrm{fg}$ per cell according to the classical definition, LOD $=3.3 \times$ standard deviation of the blank divided by the slope of the calibration curve. This value was adequate to measure the expected As concentrations at the single-cell level for the respective experimental conditions investigated. Cellular As concentrations were calculated using the following equation: ${ }^{10}$

$$
m_{\mathrm{c}}=\frac{\varepsilon \cdot Q_{\mathrm{sam}} \cdot t_{\mathrm{dwell}} \cdot\left(I_{\mathrm{C}}-I_{\mathrm{Bgd}}\right)}{m}
$$

Thereby, $m_{\mathrm{c}}$ is the mass of the element of interest in a singlecell, $\varepsilon$ is the transport efficiency, $Q_{\text {sam }}$ is the sample uptake rate, $t_{\mathrm{dwell}}$ is the dwell time, $m$ is the slope of the calibration curve and $I_{\mathrm{C}}$ and $I_{\mathrm{Bgd}}$ are the signal intensities of a single-cell event and the background, respectively. 

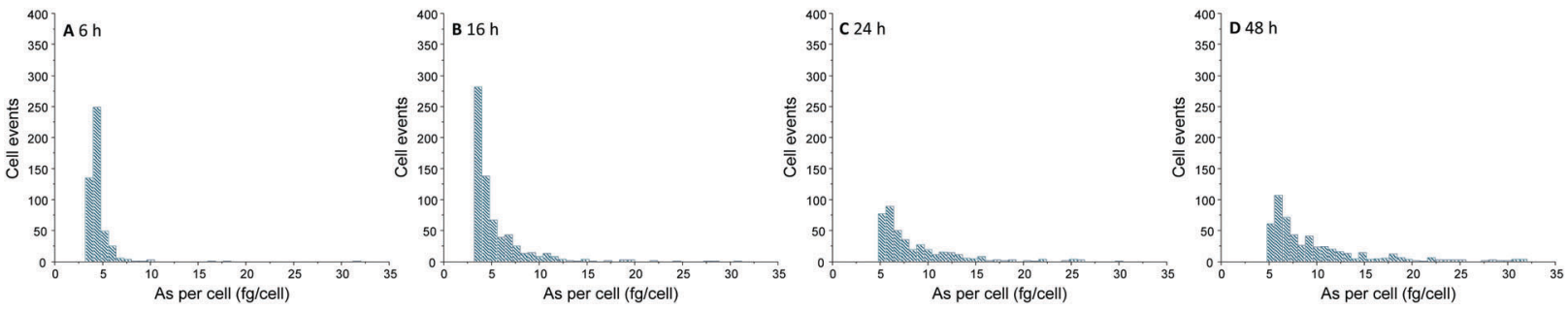

Fig. 3 Frequency histogram obtained by SC-ICP-MS/MS analysis of A549 cells treated with $25 \mu \mathrm{M}$ iAs ${ }^{\text {III }}$ for 6 (A), 16 (B), 24 (C), and $48 \mathrm{~h}$ (D).

This approach, commonly used in SC-ICP-MS, assumes that both, elemental ions present inside a single-cell as well as ions from standard solutions, behave in a similar manner on their way to the plasma. ${ }^{13}$ Many reports have shown that the plasma ionizes particles and the corresponding solved elements with a similar efficiency. ${ }^{14}$

Over the time, an increasing number of As spike signal events as well as increasing spike signal intensities on the background baseline were noted for the measurement of A549 cells incubated with $25 \mu \mathrm{M}$ of iAs ${ }^{\mathrm{III}}$ (ESI, $\dagger$ Fig. S2). For these A549 cell suspensions, the increased background baselines (as a consequence of the As release from broken cells to the aqueous media) were corrected. Subsequently, spike signals three times higher than the background baseline were collected and converted into As masses per single-cell. This way, the frequency histograms in terms of As masses per cell versus the number of cell events were obtained (Fig. 3). The lack of As spike signals for the control cell suspensions (ESI, † Fig. S2A) demonstrated that there were no spectral interferences limiting the quantitative analysis of As within single-cells. No As cell event three times greater than the background was found for A549 cells incubated for $2 \mathrm{~h}$, indicating no substantial As uptake per cell (below LOD). For longer exposure times, the number of spike signals as well as their intensities increased, demonstrating a time-dependent bioavailability of iAs ${ }^{\text {III }}$ in A549 cells.

Nevertheless, the varying intensities of the cell events and thus, different As amounts per cells show that As bioavailability of the A549 cells differs within the cell population. Thereby, the cellular amounts range from 0.4 up to more than $300 \mathrm{fg}$ per cell $\left(50 \mu \mathrm{M}\right.$ iAs ${ }^{\mathrm{III}}$ for $\left.48 \mathrm{~h}\right)$ displaying that SC-ICP-MS/MS provides more information compared to conventionally used bulk analysis.

\section{Validation of SC-ICP-MS/MS}

In order to verify the accuracy of this SC-ICP-MS/MS method, the single-cell results discussed above were compared with bulk analysis by applying an acidic microwave cell digestion ICP-MS/MS method. Therefore, cells were trypsinized, cell numbers and volumes were quantified, pelletized cells were digested in $20 \% \mathrm{HNO}_{3}$ using a closed microwave system (MARS 6, CEM Cooperation), diluted in deionized water and measured by ICP-MS/MS in the mass-shift mode using oxygen as reaction gas to eliminate interferences. $1 \mu \mathrm{g} \mathrm{L^{-1 }} \mathrm{Rh}$ was applied as an internal standard (further details ${ }^{15,16}$ ).

As presented in Table 1 the cellular As amounts determined by this SC-ICP-MS/MS analysis and by the commonly used acidic digestion of cell pellets are in a comparable range, especially for the lower exposure concentration of $25 \mu \mathrm{M}$ they were in good agreement. However, some significant differences were found for the higher As exposure concentration, which could be attributed to the different number of cells involved in providing the results, as SC-ICP-MS/MS and digestion ICP-MS/MS results correspond to 400 single-cells and 1000000 digested cells, respectively.

Despite these differences observed for A549 cells incubated at $50 \mu \mathrm{M}$, the results provided by both approaches were comparable,

Table 1 As levels in A549 cells after incubation with 25 and $50 \mu \mathrm{M}$ of iAs ${ }^{\text {III }}$ determined by SC-ICP-MS/MS and after acidic digestion followed by ICP-MS/ MS

\begin{tabular}{|c|c|c|c|c|c|c|}
\hline \multicolumn{6}{|c|}{ SC-ICP-MS/MS } & $\begin{array}{l}\text { Acidic microwave digestion } \\
\text { followed by ICP-MS/MS }\end{array}$ \\
\hline $\begin{array}{l}\text { Exposure } \\
\text { time }[\mathrm{h}]\end{array}$ & $\begin{array}{l}\text { Exposure } \\
\text { dose }[\mu \mathrm{M}]\end{array}$ & $\begin{array}{l}\text { Mean } \pm \mathrm{SD} \\
{[\text { fg As per cell }]}\end{array}$ & $\begin{array}{l}\text { Min } \\
{[\text { fg As per cell }]}\end{array}$ & $\begin{array}{l}\text { Median } \\
{[\text { fg As per cell] }}\end{array}$ & $\begin{array}{l}\text { Max } \\
{[\text { fg As per cell] }}\end{array}$ & $\begin{array}{l}\text { Mean } \pm \mathrm{SD} \\
{[\text { fg As per cell] }}\end{array}$ \\
\hline 0 & - & $<\mathrm{LOD}$ & - & - & - & $0.02 \pm 0.02$ \\
\hline \multirow[t]{2}{*}{2} & 25 & $<$ LOD & - & - & - & $0.6 \pm 0.1$ \\
\hline & 50 & $<$ LOD & - & - & - & $1.2 \pm 0.2$ \\
\hline \multirow[t]{2}{*}{6} & 25 & $3.9 \pm 0.7$ & 0.6 & 1.7 & 56.9 & $7.0 \pm 0.1$ \\
\hline & 50 & $3.2 \pm 0.4$ & 0.4 & 1.9 & 33.1 & $13.8 \pm 0.3$ \\
\hline \multirow[t]{2}{*}{16} & 25 & $7.1 \pm 0.7$ & 0.4 & 3.4 & 339.8 & $8.5 \pm 0.3$ \\
\hline & 50 & $12.9 \pm 0.9$ & 0.5 & 7.5 & 147.6 & $19.2 \pm 1.6$ \\
\hline \multirow[t]{2}{*}{24} & 25 & $10.4 \pm 1.2$ & 0.4 & 5.8 & 105.8 & $9.7 \pm 0.4$ \\
\hline & 50 & $20.2 \pm 2.3$ & 0.4 & 12.8 & 166.5 & $28.0 \pm 0.9$ \\
\hline \multirow[t]{2}{*}{48} & 25 & $15.0 \pm 1.5$ & 0.4 & 7.3 & 199.3 & $12.2 \pm 0.5$ \\
\hline & 50 & $42.6 \pm 0.9$ & 0.4 & 22.7 & 338.6 & $35.1 \pm 4.3$ \\
\hline
\end{tabular}


demonstrating the feasibility and reliability of SC-ICP-MS/MS to quantify As at a single-cell level. SC-ICP-MS/MS results present a more realistic scenario, proving that identical cells respond differently and contain different As contents after treatment, whereas for digestion ICP-MS/MS the same As uptake is assumed for the whole cell population masking the individual cellular response. The cellular arsenic concentrations obtained with both methods are thereby in good agreement with the literature. ${ }^{9}$

\section{Conclusions}

This study demonstrates that SC-ICP-MS is a solid alternative to the commonly used digestion protocols for the assessment of cellular arsenic bioavailability. Thereby, this method is less time-consuming as pelletized cells are re-suspended in water and can be directly measured. This procedure avoids the permeabilization of the cell membrane and thus also avoids the loss of cytosolic metal species which is normally caused by cell fixation. Information on metal distribution among the cell population is, in contrast to bulk analysis, still available and gives further insights into uptake, accumulation and release on the single-cell level. However, short dwell times of a few ms are needed and for the calculation of single-cell metal levels by external calibration the cell transport efficiency has to be determined. Therefore, sulfur and phosphorus can be used which are frequently and at a constant level present in cells.

\section{Conflicts of interest}

There are no conflicts to declare.

\section{Acknowledgements}

This work was supported by NutriAct - Competence Cluster Nutrition Research Berlin-Potsdam funded by the Federal Ministry of Education and Research (FKZ: 01EA1408B). This work was further funded by TraceAge DFG Research Unit on Interactions of essential trace elements in healthy and diseased elderly, Potsdam-Berlin-Jena (FOR 2558/1). We thank the Marie Curie Actions, Horizon 2020 for the financial support of Ana López-Serrano.

\section{References}

1 K. Kleparnik and F. Foret, Recent advances in the development of single cell analysis - a review, Anal. Chim. Acta, 2013, 800, 12-21.

2 E. J. Lanni, S. S. Rubakhin and J. V. Sweedler, Mass spectrometry imaging and profiling of single cells, J. Proteomics, 2012, 75, 5036-5051.
3 R. Trouillon, M. K. Passarelli, J. Wang, M. E. Kurczy and A. G. Ewing, Chemical analysis of single cells, Anal. Chem., 2013, 85, 522-542.

4 G. Cerchiaro, T. M. Manieri and F. R. Bertuchi, Analytical methods for copper, zinc and iron quantification in mammalian cells, Metallomics, 2013, 5, 1336-1345.

5 M. Milic, G. Leitinger, I. Pavicic, M. Zebic Avdicevic, S. Dobrovic, W. Goessler and I. Vinkovic Vrcek, Cellular uptake and toxicity effects of silver nanoparticles in mammalian kidney cells, J. Appl. Toxicol., 2015, 35, 581-592.

6 K. S. Ho and W. T. Chan, Time-resolved ICP-MS measurement for single-cell analysis and on-line cytometry, J. Anal. At. Spectrom., 2010, 25, 1114-1122.

7 T. Nomizu, S. Kaneco, T. Tanaka, D. Ito, H. Kawaguchi and B. T. Vallee, Determination of Calcium Content in Individual Biological Cells by Inductively-Coupled Plasma-Atomic Emission-Spectrometry, Anal. Chem., 1994, 66, 3000-3004.

8 I. L. Hsiao, F. S. Bierkandt, P. Reichardt, A. Luch, Y. J. Huang, N. Jakubowski, J. Tentschert and A. Haase, Quantification and visualization of cellular uptake of $\mathrm{TiO}_{2}$ and $\mathrm{Ag}$ nanoparticles: comparison of different ICP-MS techniques, J. Nanobiotechnol., 2016, 14, 50 .

9 F. Ebert, A. Weiss, M. Bultemeyer, I. Hamann, A. Hartwig and T. Schwerdtle, Arsenicals affect base excision repair by several mechanisms, Mutat. Res., 2011, 715, 32-41.

10 H. Wang, B. Wang, M. Wang, L. Zheng, H. Chen, Z. Chai, Y. Zhao and W. Feng, Time-resolved ICP-MS analysis of mineral element contents and distribution patterns in single cells, Analyst, 2015, 140, 523-531.

11 A. Montaser, Inductively Coupled Plasma Mass Spectrometry, Wiley-VCH, New York, 1998.

12 S. D. Fernandez, N. Sugishama, J. R. Encinar and A. SanzMedel, Triple Quad ICPMS (ICPQQQ) as a New Tool for Absolute Quantitative Proteomics and Phosphoproteomics, Anal. Chem., 2012, 84, 5851-5857.

13 L. N. Zheng, M. Wang, B. Wang, H. Q. Chen, H. Ouyang, Y. L. Zhao, Z. F. Chai and W. Y. Feng, Determination of quantum dots in single cells by inductively coupled plasma mass spectrometry, Talanta, 2013, 116, 782-787.

14 L. Ebdon, M. E. Foulkes and S. Hill, Direct atomic spectrometric analysis by slurry atomisation. Part 9. Fundamental studies of refractory samples, J. Anal. At. Spectrom., 1990, 5, 67-73.

15 T. A. Marschall, J. Bornhorst, D. Kuehnelt and T. Schwerdtle, Differing cytotoxicity and bioavailability of selenite, methylselenocysteine, selenomethionine, selenosugar 1 and trimethylselenonium ion and their underlying metabolic transformations in human cells, Mol. Nutr. Food Res., 2016, 60, 2622-2632.

16 S. Meyer, M. Matissek, S. M. Muller, M. S. Taleshi, F. Ebert, K. A. Francesconi and T. Schwerdtle, In vitro toxicological characterisation of three arsenic-containing hydrocarbons, Metallomics, 2014, 6, 1023-1033. 